\title{
Necessity of Knowledge Management Practices in TVET Projects in Nepal
}

\author{
Devendra Adhikari ${ }^{1}$ \\ Independent Researcher \\ Corresponding Email: devendra.adhi84@gmail.com
}

\begin{abstract}
Unemployed youths in Nepal have been receiving vocational training through different projects with the support of international donor communities. Many of these projects simply meet their objectives by fulfilling the quotas of the training participants. There are some TVET projects in Nepal, which do not have priorities in sharing the learning and good practices that were gained during their implementation period due to the lack of Knowledge Management (KM) and disseminating mechanism. The purposes of this article are (i) to disseminate some activities and learnings gained by a Technical Education and Vocational Training (TVET) Project in Nepal which trained nearly 3000 youths from 2012-2016, and (ii) tracing out the importance of the KM practices in every TVET projects. This is a case study research in which secondary information such as the review of the project documents and the reflections of the author as a practitioner-scholar have been used as data. The findings of this research reveal that every TVET project in Nepal has gathered vast sources of knowledge and data. These learning will be beneficial to other forthcoming projects of similar nature. If these data and knowledge are shared among other TEVT project's, then huge financial resources of the state will also be saved. This research article could help us to consider about the importance of KM system in TVET projects.
\end{abstract}

Keywords: Knowledge management, Vocational training, Mobile skill-training

\section{Context}

The Government of Nepal has been providing shortterm vocational training to thousands of youths annually to enhance their livelihood. The fifteenth periodic plan of Nepal has also highlighted that five lakh Nepalese youths enter the labor market annually and the country is putting its best effort to provide them vocational trainings; however, only $30 \%$ of the youths are able to receive the trainings (National Planning Commission, 2020a). In essence, the intention of the government to skill the youths and the aspirations of the youths to empower themselves through skill trainings seem resonant in the case of Nepal.

1 Author worked as the Training Monitoring Officer in 'The road project' in Nepal which trained nearly 3000 youths from 2012-2016. The interpreted views in this article belong to author only. 
In this scenario, a road construction cum livelihood improvement project (referred hereafter as 'the road project') was agreed to be launched between one of the line ministries of the Government of Nepal and the Asian Development Bank in 2012. The road project had aimed to reduce rural poverty in 18 districts in remote hilly and mountain regions of Nepal: Taplejung, Solukhumbu, Okhaldhunga, Ramechhap, Lamjung, Gorkha, Myagdi, Baglung, Dolpa, Humla, Jajarkot, Jumla, Kalikot, Mugu, Baitadi, Bajhang, Bajura, and Darchula. Every district comprised the team, which was led by the in-charge of the District Technical Office. The project was focused on increasing the rural incomes through several aspects such as vocational training, improving access to credit for the rural poor, capacity building of the local people, decentralized governance, fostering rural transport connectivity, and building community infrastructures. Regarding the achievements of the road project, a local newspaper quoted that the project had attained cent percent of the physical progress against the target.

The primary activity of the road project was to construct roads in the rural districts of Nepal. Despite this, it organized the National Skill Testing Board (NSTB) level one vocational trainings to the people who had been either affected or benefitted from the road. The road project chose skill development strategy as one of the powerful tools to reduce human poverty (Bhatta, 2014). The district teams conducted Training Needs Assessment (TNA) to identify potential trainees with established eligibility criteria such as age, academic qualification, loss of property by the road, interested trainings, and future plans. During the four years of implementation nearly 3,000 beneficiaries received the vocational training through the project.

\section{Knowledge Documentation and Dissemination in TVET Projects}

The internationally aided project with huge budget had envisaged a target of skilling 3000 unemployed youths in 18 project districts of Nepal. TNA was done in the initial phase. The training programs were conducted from January 2015 to December 2016 in 27 different NSTB level one occupations. This concept of skilling the youths was guided by the welfare state model of development where the "state's power is deliberately used to modify the normal play of economic forces to obtain a more equal distribution of income for every citizen" (Abraham, n.d as cited in Dahal, 2005, p. 20).

The road project was phased out in 2016. It achieved its target to skill 3,000 youths from geographically diverse regions in Nepal. However, most of the TVET stakeholders are still unaware of the knowledge earned during the road project implementation. This could be due to the lack of knowledge management and dissemination unit in the project. Even CTEVT might not be aware of the activities and learning that occurred along with the TVET component of the project. The purposes of this research paper are (i) to disseminate some of the learnings and good practices of the TVET component of the project, and (ii) to identify the need of a knowledge management mechanism in TVET projects in Nepal.

\section{Research Methodology}

The paper is based on qualitative study, followed by the interpretative paradigm applying the case study approach. The TVET component of the road project has been taken as the case in this research. The project documents and the author's reflection are the units of analysis. Case study research implies more than one method to gather field evidences (Yin, 2018). Firstly, the author has reviewed the training guidelines, TNA reports, training completion reports, training effectiveness survey reports, and Project Administration Manual (PAM) of the road project. Secondly, being practitioner-scholar, the author has interpreted the data through self-reflections and experiences learned during the working tenure in the project. The author has considered document analysis in this article as a scholar has also claimed that document analysis can be used as a "main method of data collection and analysis" (Owen, 2014, p. 9). Eventually "the qualitative researcher 
is expected to draw upon multiple sources of evidence [...] to seek convergence and corroboration through the use of different data sources and methods [...] such sources include interviews, participant or nonparticipant observation, and physical artifacts "(Yin, 1994 as cited in Bowen, 2009, p. 2).

The quality standard of the research has been maintained by reviewing the authorized project documents. The presentation of this research paper in an International Conference of Technical and Vocational Education and Training 2019, at Dhulikhel, Nepal, and incorporating the feedback from the audiences have enriched the discussion in this paper. Regarding the ethical consideration, the author believes that documenting and disseminating information regarding the vocational training component of the road project will not harm any of the then project officials, donors, beneficiaries, government agencies, and all. The documentation of the findings and disseminating the TVET knowledge of the road project might not breach any clauses of the employment contract, which the author had signed with the then employer organization. The italicized phrase, 'the road project' in this article will refer to the same government project which skilled 3000 youths from 18 rural districts of Nepal from 2012-2016, and the learning has been shared in this article. More importantly, the name of the project has been kept anonymous due to difficulty in getting response from the then employer organization to the author's email with regard to this article publication.

\section{Theory of Knowledge Management}

Knowledge Management is a byproduct of human experiences, with the combination of the information, data, and procedures (Igbinovia \& Ikenwe, 2017). It is a part of organizational work in which there comprises a responsible unit with well-defined procedures to collect and share the learnings. A structure is an essential component in managing the knowledge of any institution. "Knowledge Management can transform organizational levels in term of effectiveness, efficiency, and scope of operation, using advanced technology, data, and information that are made available to users for effective productivity (Dhamdhere, 2015, p. 168). Dhamdhere also claims that knowledge management in an institution is not only useful for building knowledge, but helps in solving organizational issues and supports in effective decision makings. Similarly, gathering of knowledge, its mass dissemination, and its utilization by the employees always bring new changes in an organization (Plessis, 2007, as cited in Obediat, Al-Suradi, Masa'deh, \& Tarhini, 2016).

From the neo-liberal perspectives, the outputs of a profit-oriented business are guided by "shorten product development time, [...] empower employees, innovate and deliver high-quality products, enhance flexibility and adoption, capture information, create knowledge, share and learn" (Bhojaraju, 2005, p. 39). These yields are possible if the institution has a functional KM system. Bhojaraju also stresses that the KM mechanism consists of people, process, and technology, and "KM cannot be just another project on the side" (p. 49). Thus, KM is useful to disseminate new ideas, cases, and best practices learned in an institution within the team and to the outside mass.

\section{Findings and Discussions}

The findings and discussions in this paper has been divided into two sections. The first section includes several activities and learning made in the road project during the pre-training, during training and post-training phases. The second section includes the interpretation of the road project's activities from the perspective of knowledge management theory.

\section{Pre-training Phase}

Initially, the road project selected 40 roads to be constructed by the local building groups in 18 districts of Nepal. Alongside, the district teams were given an orientation to conduct the TNA in the communities through the checklists. There, two prioritized groups were identified to receive the trainings. The first group included the households listed in the Resettlement Plan (RP), whose land or any physical 
properties were occupied or damaged due to the roads construction. The second group included the Disadvantaged-group households (DAGs HHs) listed in the Gender Exclusion and Social Inclusion plan (GESI). Besides this, the interests of the participants in receiving the training, their educational status, age, gender, future plan after receiving the training, readiness to travel to another district to receive the training if necessary, and having the Nepalese citizenship were inquired and documented in the TNA forms.

The road project did not conduct any Rapid Market Appraisal (RMA) as it might have perceived that the trained graduates could bring about changes in the local economy through various small-scale enterprises or skillful engagements in the jobs. The TNA survey listed out the interested trades of the participants which could fill the skill gaps in the local markets. The open T.N.A identified a large number of training trades which was planned to be conducted accordingly. However the road project learned that it was not easy to organize NSTB skill tests with a group size of less than 10 participants. The per-head exam cost of the training events with low number of participants was higher than it was envisaged earlier. Due to which, either some of such trainings were not conducted or even if conducted, no NSTB skill tests were organized. As predicted by the road project's PAM, there had to be at least $40 \%$ females and $60 \%$ DAG HHs representation in the training programs but the target of female participants could not be fulfilled. This happened because only $33 \%$ of females showed their interests during the TNA survey and their number could not be increased during the training programs as well.

Regarding the nature of the training programs, mobile-based, center based, and apprenticeship training activities were planned by the road project and Training Service Providers (TSPs). Two TSPs were selected to provide skill trainings to the participants. The centrally based training venues were planned at common places, mostly in the cases which had the participants from the different districts.
The participants were asked to gather and form a group of 20 individuals. The TSPs provided free hostel facilities and food services to the participants which was later reimbursed by the road project. The training venues were managed by the TSPs with necessary tools and equipment, qualified trainers, and necessary logistic arrangements for the trainees. Most of the training events were centralized because the road project and TSPs had to abide by the (silent) norms of NSTB regarding the requirement of minimum group size of the participants, i.e. either 10 or 20 participants while conducting the skill testing exams. Some of the mobile-based training venues were planned in the project districts or even nearby the road construction sites, where the training group with the minimum number of required participants could be formed for attending on NSTB skill test. An apprenticeship training on Bamboo Handicraft maker was also conducted by the project.

The road project had developed training codes for the easy administration of the training programs. For instance, every trainee's detail was recorded with the unique identification number, such as P1-03 means $\mathrm{P} 1=$ Package $\mathrm{I}$, and $03=$ Trainee number 03 . Likewise, the separate code was provided to every training event, such as P01-T05-19 which means P01= Package I, T= Tailoring trade, 05= Fifth event, $19=19$ number of trainees. These codes were found to be helpful during the data entry work, file management, and report circulation within the project team. The training programs were conducted in the form of four different packages.

Before sending the participants to the training programs, every district team conducted an orientation programs to inform the participants about their rights, roles, and responsibilities during the trainings. The participants coming to the training venue had to bring a recommendation letters from the district teams, with included the information such as their gender, age, belonging to RP or GESI groups, interested training trades, and if they need the childcare facilities during the training program. The TSPs used the letters as referent in providing different 
facilities to the participants. These letters were also the evident documents for the TSPs for reimbursing the expenses during the training program.

The curricula of some trades, which were listed in the TNA report but not available in the market, were developed by the related subject experts of the TSPs and the road project. The new curricula that were developed are: 160 hours Light Vehicle Driving training, 160 hours Basic Computer Operator training, 160 hours Small Teashop and Hotel Management training, 390 hours Bamboo Handicraft Maker training, and 160 hours Three-phase Electrician training. The technical and the vocational training experts from the TSP (of package 01) and the road project were involved in designing the 10 days (70 hrs) Earthquake Resilient Building Technology (ERBT) training for skilled Masons. ERBT training was provided to the 99 participants, immediately after the devastating earthquake in April 2015 in Nepal.

\section{During Training Phase}

Different activities were performed during training implementation stage in the road project. The participants were provided NSTB level one training and the majority of them appeared in skill-testing exams. Apart from the formal trainings, the trainees received market oriented skills in some of the training events.

Although the road project was officially launched in 2012 A.D, the field-based TVET trainings only began from January 2015. The initial 36 months were consumed while conducting the TNA, makings plans, and selecting the TSPs. The road project only had a period of 24 months to provide training to 3000 participants. There was a long time gap between the TNA conduction and the training implementation time, which demotivated many of the interested participants. This consequently resulted in the high rate of replaced trainees in the training programs. Most of the female participants who had shown interest during TNA survey could not appear because many of them got married and were out of the villages. Similarly, many youths had already left the villages as they had to go for work in the nearby cities or abroad. Some of them even changed their mindset to go to another district or even to the nearby cities for the training by leaving homes for nearly two and a half months. The replaced trainees were identified through re-TNA processes by the district teams.

The road project only provided basic level skill training to its aspirants, which is also termed as NSTB level one. This was quite helpful for the novice learners but some of the participants who were already engaged in works in the concerned trades expected advance training (level two) from the road project. Some of these experienced trainees, who had already achieved mastery in the skills enrolled in the training only to get the certificate from NSTB. Unfortunately, TNA survey could not identify these concerns of the participants. The life skill trainings such as self-awareness, gender and domestic violence, adolescence and reproductive health, communication, decision making and goal setting, self-management, exploitation and human trafficking, and enterprise development, were blended along with the technical trainings by the professional trainers of TSPs.

The training programs were designed to be residential, except for those which could be conducted at the settlement levels in the project districts. The road project had provided daily subsistence allowance, food, and lodging services to all the trainees. Some of the training groups received post-training tools/kit support in the trades approved by the road project. There were childcare facilities at training venues, for the children of age 3 or below. There was provision of group insurance for the trainees. The participants also got transportation facilities to reach the training venue and return to home, as per the agreed norms. The trainees from Humla and Dolpa were provided with airfare cost as per actual, to reach the Nepalgunj training venue and fly back to their district. Despite these facilities, the road project and TSPs noted and addressed the genuine grievances of most of the participants which were dominantly 
focused on the services such as food, lodging, recreation, childcare, and less transportation cost. It was interesting to learn that the participants were more concerned about the provided logistics, rather than the core training programs.

The professional trainers and the local management teams of TSPs embedded some innovative ideas in the training programs. During a Basic Computer training event at the Itahari venue, the trainees learned market-oriented skills such as designing a biodata, training application forms, certificates, institutional logos, photoshop including photo sizing and designing, document scanning, and Basic English language. During an Assistant Beautician training event at venue in Kathmandu, a local beauty fair was organized by the trainees accompanied by their trainers at Sitapaila during the Teej festival, where free services were provided to the visitors. The free services included threading, Juro $^{2}$, Mehendi ${ }^{3}$, and hair cutting. From the beauty fair, the participants learned guest-handling and customer care skills and built up their confidence by working at a real work place. The trainees also participated in a beauty seminar at Kathamandu which helped them to enlarge their professional network. During a Mobile Phone Repairer training at a venue in Kathmandu, the trainees visited the wholesale markets of mobile accessories at Maha Boudha area, where they observed and studied the market closely. During a Tailoring training (basic) at a venue in Kathmandu, trainees learned how to sew shirts and pants as part of the market-oriented skills. They also sewed Kurtasalwars as their training uniforms. The trainees also learned how to sew cotton bags, handkerchiefs, purses, face masks, and pot-holders. At the end of the Tailoring training, the trainees were provided with all their sewed dresses and in return they were asked to display their work in their future enterprises. During the Junior Plumber, Building electrician, and Bricklayer Mason trainings at a venue in Kathmandu, the participants had a chance to undergo on the job training (OJT) at the real workplaces. During a Community Livestock training at a venue in Chitwan, the resource persons from the Lumbini Kennel Club and District Livestock Office delivered lectures on dog diseases, commercial livestock farming, and livestock diseases. During a Light Vehicle Driving training event at a venue in Chitwan, the Traffic police personnel conducted classes on traffic rules, license form filling, road accidents, and road safety measures. During Nursery Assistant, Junior Poultry Technician, and Bee Keeper training events at Chitwan venues, the participants went on field visits and observed the trade-related enterprises and interacted with the local entrepreneurs. During a Dental Chair-side Assistant training at a venue in Kathmandu, the trainees learned some practical skills under the supervision of experts at Universal Dental Hospital and Training Center. A participant of a Bakery training at venue in Kathmandu learned Continental cooking as well. The participants of a Micro-hydro assistant event at Kathmandu venue visited the micro-hydro plants at Kavrepalanchok, where they learned the practical operation skills of micro-hydro plants and the role of community in managing the plants. During an Indian Cook training event at Chitwan venue, the trainees made exposure visits to Global Hotel, Central Palm Hotel, and Royal Century Hotel at Bharatpur and Sauraha area where they observed the staff management, kitchen, food serving units, hygiene of staff, guests welcoming procedure, gardening work, parking management, personal relation skills, and security provisions in the star hotels.

\section{Post Training Phase}

In the post-training phase, the follow up of the trained graduates was done by conducting effectiveness surveys by the district teams of the road project. There were several positive impacts of the trainings in enhancing the livelihood of the participants. Apart from this, 4 out of 10 unemployed respondents replied that they were not engaged in any earning activities after the training because of their economic problem which prevented them to start their ownenterprises. One of the notable findings of the survey was that almost $15 \%$ of the training participants were 
from Light Vehicle Driving trade, and the participants were uncertain about their future because they did not have a driving licenses after the completion of the training. In Nepal, the Department of Transport Management is the only responsible government body to organize the driving license exams and certify the successful candidates. The road project had developed and implemented the curriculum of Light Vehicle Driving by incorporating some practical courses on vehicle repairing, to make the participant's skill saleable after the trainings. However, the graduates of the driving trade were found to be unemployed even after they were skilled.

The survey of the participants also suggested that there should not be a long duration gap between the TNA and training implementation time because most of the interested people identified during TNA were not available for the training due to this long gap. The survey of the participants also recommended that advance training and financial support should be provided to the successful and capable training graduates so they can establish their enterprises. The informants urged that CTEVT should not delay in publishing the NSTB result because it discouraged many participants to search for jobs immediately after the completion of the training program. Some of the female participants also shared that skill training programs conducted at the villages (mobile skill development and training program) were helpful for them since they could attend the programs by managing their daily works at home. In Nepal, the importance of short-term mobile skill development and training has been realised from scholarly (Adhikari, 2019), policy (National Planning Commission, 2020a), and practice (National Planning Commission, 2020b) perspectives in recent period. The participants also proposed some alternative ways to connect the skill development programs in bringing the changes in the lives of the participants such as promoting horticulture, herbal farming and processing, fruit juice making, livestock rearing, dairy management, market development, and cooperative management for the holistic development of the region. The informants were signaling to link the road connectivity component of the road project with its skill training program. Despite these facts, the road project could not focus on all these important trainings as they were not identified during the TNA process. Thus, an integrated approach of TNA and RMA in the road construction cum skill development projects could be helpful to address the participants' aspirations in filling their skill gaps and to mobilize the agriculture-based economy through the newly developed networks of road.

\section{Project's Target Achieved, but Learnings?}

A road construction cum livelihood improvement project worked with the right based and the needbased notions of development in Nepal. It was the right of rural people to have an access to decentralized development through road connectivity and livelihood improvement programs. TNA was conducted in the communities to document the local's needs in different vocational training activities. In this regard, Chambers (1983) has also mentioned that sitting, asking, and listening is the best method for an outsiders to get closer with the community people. These down to earth interactions with beneficiaries could help the development practitioners to learn from the rural people and plan the necessary development activities with everyone's involvement and ownership accordingly.

In the road project, the TSPs conducted the training programs in different project districts or other nearby venues. The participants were enthusiastic in learning new skills and hopeful that it would improve their livelihood. The trainees received different facilities such as daily subsistence allowance, transportation allowance, food and lodging, and childcare during the training programs. Some of the participants also received free tools/kit in the selected trades and also attended the skill test exams, where the costs were borne by the road project. Shrestha (2009) has also stated that state-led development strategies are welfare-oriented. The initiation of the road project to skill the thousands of youths benefitted the grassroot beneficiaries, which further encouraged them to contribute to the local development process in the 
project districts (Patnaik \& Becker, 1999 as cited in Ericson and Stahlbrost, 2006).

The road project experienced different learning, overcoming strategies, and some of the best practices in the TVET sector in Nepal. Firstly, the learning of the pre-training phase were the approaches of TNA conduction, trainees' selection, and selection of TSPs, planning of the training activities, development of the training identification codes, designing the training monitoring formats, and designing of the new curriculum which was unavailable in the local market. Secondly, during the training implementation phase, the road project's focus was on maintaining the quality standard of the training, applying safety measures at the training venues, facilities provided to the residential and other participants, grievance handling of the participants, and arranging the NSTB skill tests at mobile training venues. Thirdly, during the posttraining phase, the road project did follow up survey of its graduates through random sampling in all project districts. It documented the views of its team members and surveyed participants with regard to the positive and developmental aspects of the vocational training component of the road project. The collection and sharing of successful case studies by the district teams were helpful to record the best practices of the road project's outcome. The other learnings of the road project were the findings of TNA reports and disaggregate data such as age, gender, ethnicity, address, and NSTB pass results of nearly 3000 trainees from 18 project districts. The designing of new training curriculum of six shortterm training trades, imparting the market-oriented skills in the training programs apart from the curriculum, implementing the residential training model which provided different facilities to the participants, and attaining high NSTB pass out rates were some of the key achievements of the road project.

However, all these learning experiences were shared only within the team members for internal reporting purposes. There was no knowledge management unit in the road project to disseminate the best practices, challenges, success and failure cases, and training data (not all due to ethical concerns, but at least TNA report and NSTB report) with other TVET stakeholders. So far it is known, even CTEVT does not have any clear guidelines regarding the knowledge disseminating mechanism for any TVET projects in Nepal. Although the CTEVT strategic plan 20142018, mentioned to develop and update the CTEVT knowledge management system by 2015 , it seems not working effectively until now as the country has got new and decentralized governing structures at local levels (CTEVT, 2014). Many TVET projects in Nepal, even under the government units seem like haphazardly planning and implementing the training activities. There is no centralized data system to know the learnings of such projects and the posttraining status of the training recipients. CTVET also seems uninterested in gathering and documenting the data of training recipients, the ideas, challenges, coping strategies, best practices, and success and failure cases in different TVET projects. The knowledge documentation and dissemination could help in designing other similar TVET projects in Nepal. Thus, a KM mechanism in every TVET project is utmost important in Nepal, as it helps to do,[...] "knowledge capture and /or creation [...] knowledge sharing and dissemination [...] knowledge acquisition and application" (Dalkir, 2005, p. 43).

Apart from knowledge centralizing and disseminating, the framework for KM could facilitate as a discussion forum among TVET projects and training service providers where they can share each other's experiences. The macro picture of the framework could be: Every TVET project will have an internally active knowledge management unit to gather its own project related information. This gathered knowledge from different TVET projects will be centralized, properly documented, and disseminated through a responsible central unit. In the first phase, it could begin with the piloting of few TVET projects under CTEVT and the Ministry of Education. In the second phase, it could be expanded to all TVET projects across the country. 
In the third phase, this model should encompass all the 1081 training service providers in Nepal, which contributions and learnings from TVET sector development should not be undermined (Ministry of Education, Science \& Technology, 2019b). These practices will institutionalize a knowledge led TVET development practice in Nepal, which will have a pivoting role in the mainstreaming the TVET sector as the formal education sector of the country (National Planning Commission, 2020a). And of course, it is no doubt that CTEVT is efficient to take a lead on this concern.

One of the TVET advocators of Nepal, Dr. Bhawani Shankar Subedi has been constantly lobbying in "the need and importance of having a central database system to achieve each and every TVET related piece of information and having an effective national TVET MIS system for that" (United Nations Development Program, 2016a). Likewise, the Educational Policy 2019 in Nepal has highlighted the need to incorporate the "Integrated Educational Management Information System" to develop a formal education system through a collaborative approach among local, federal, and central governments (Ministry of Education, Science \& Technology, 2019a, p. 11). These views signal that the TVET sector in Nepal needs an effective KM system for its development.

\section{Conclusions}

The road project in Nepal, which skilled nearly 3000 youths from 2012-2016 has added a milestone in the short-term vocational training sector. The knowledge gained by the road project could be helpful to the policymakers and TVET practitioners in formulating appropriate plans and policies for the improvement of the TVET sector. However, it could be blamed that the road project and similar other TVET projects did not share their learnings and best practices with other TVET stakeholders of Nepal. This is probably because of the absence of the Knowledge Management mechanism in the TVET projects in Nepal. Igbinovia and Ikenwe (2017) have even pointed, "KM is basically made up of three components of processes, people and systems, which must be effectively managed to meet the objective of any knowledge management practice" (p .35). The 'system' aspect of knowledge management can be developed by establishing KM units in every TVET projects.

TVET projects initiated by the Government of Nepal are of course, essential in bringing changes in the lives of rural people, but they are equally blamed for creating multi-centers in imparting the training programs to the grass-root people. This could be because these projects enjoy autonomy in not/sharing field learning and data with others. Neither the employment status of the skill graduates is properly documented and disseminated. This could probably cause replication of the training activities for the same region, for the same people, and by conducting the time and again baseline surveys such as training needs assessment, rapid market appraisal, and others related to the project. The effort and resources of the forthcoming projects are being wasted, simply because they do not have access to the data, field learnings, best practices, and success and failure cases of previous TVET projects in Nepal. Ministry of Education, Science \& Technology has even mentioned that:

In Nepal, TVET programs are run by government agencies, non-government organizations, private firms, as well as projects supported by different donor agencies. Some fifteen line ministries are also offering TVET programs. However, coordination among the organizations providing TVET programs and the availability of information and data regarding the same is acking. (Ministry of Education, Science \& Technology, 2017, p. 6)

Most of TVET projects in Nepal have only internalized knowledge dissemination system. A review report by United Nations Development Program has also mentioned that "there is need to have policy dialogue on the TVET contexts of Nepal, TVET needs, gaps in the policies, engagement of 
the private sector, provision of competency-based training curricula development" (United Nations Development Program, 2016b, p. 2). Isn't it time to think about this? The present situation of creating multi-centers through different vocational training projects in terms of identifying the training needs at communities, training implementation, curriculum design, conducting training effectiveness surveys, and centralizing the knowledge, needs some reforms. These projects should be networked, at least for knowledge sharing and disseminating purposes. This initiation will help to share the best practices, success, and failure cases, and TVET data to all stakeholders. This move will also prevent the replication of vocational training programs to the same target group and fresher will get the opportunities. This initiation could save a large budget and preparation time of the TVET projects in the country. CTEVT should take a lead on this. This article is not against the decentralization of the TVET plans and activities; however, the knowledge centralization, documentation, and dissemination is essential for the development of TVET in Nepal.

\section{Note}

This paper is revised and the extended version of the paper, titled 'Knowledge Management in TVET' which was presented and its abstract was published at International Conference on TVET, 2019 (ICTVET 2019), held at Dhulikel, Nepal on September 11-12, 2019.

\section{References}

Adhikari, D. (2019). Cosmological orientation in promoting the enrollment in short-term mobile skill-trainings: A narrative inquiry on women's lives in Nepal. Journal of Training and Development, 4, 34-45. https://doi.org/10. 3126/jtd.v4i0.26835

Bhatta, K. (2014). How can vocational education and training play an important role in poverty reduction in Nepal? Technical and Vocational Education and Training Development Journal, 1 (14), 71-75.
Bhojaraju, G. (2005). Knowledge management: Why do we need it for corporates. Malaysian Journal of Library \& Information Science, 10(2), 37-50. Retrieved from https://papers.ssrn.com/ sol3/papers. cfm?abstract_id=3375572

Bowen, G. (2009). Document analysis as a qualitative research method. Qualitative Research Journal, 9(2), 27-40. https//10.3316/QRJ0902027

Chambers, R. (1983). Rural development: Putting the last first. London: Longman.

Council for Technical Education and Vocational Training (2014). CTEVT strategic plan 2014 2018. Kathmandu: Author.

Dahal, R.K. (2005). Rajya ra gramin bikas [State and rural development]. Kathmandu: Dikshyanta Publication.

Dalkir, K. (2005). Knowledge management in theory and practice. London: Elsevier.

Dhamdhere, S. N. (2015). Importance of knowledge management in the higher educational institutes. Turkish Online Journal of Distance Education, 16(1), 162-183.

Ericson, A. \& Stahlbrost, A. (2006). In search of innovation: Grasping the concepts of needs. International Journal of Technology, Knowledge and Society, 2(4), 35-44.

Igbinovia, M. O., \& Ikenwe, I. J. (2017). Knowledge management: Processes and systems. Information Impact: Journal of Information and Knowledge Management, 8(3), 26-38.

Ministry of Education, Science \& Technology. (2017). Comprehensive TVET annual report. Kathmandu: Author.

Ministry of Education, Science \& Technology. (2019a). Rashtriya sikshya niti 2076 [National education policy 2019]. Kathmandu: Author.

Ministry of Education, Science \& Technology. (2019b). Technical and vocational educational 
and skills development: Fact sheet, 2076. Kathmandu: Author.

National Planning Commission. (2020a). Pandhrau yojana 2076/77-80/81 [Fifteenth plan 2019/20 2023/24]. Kathmandu: Author.

National Planning Commission. (2020b). Barsik bikas karyakram 2077/78 [Annual development program 2020/21]. Kathmandu: Author.

Obediat, B. F, Al-Suradi, M. M, Masa'deh, R. \& Tarhini, A. (2016). The impact of knowledge management on innovation: An empirical study on Jordanian consultancy firms. Management Research Review, 29 (10), 1214-1238. https// 10.1108/MRR-09-2015-0214

Owen, G. T. (2014). Qualitative methods in higher education policy analysis: Using interviews and document analysis. The Qualitative Report, 19(52), 1-19. Retrieved from http://www.nova. edu/ssss/QR/QR19/owen52.pdf

Shrestha. M. (2009). Community development. Kathmandu: Quest publication.

United Nations Development Program. (2016a). Knowledge management and knowledge networking for the development of technical vocational education and training. Kathmandu: Support to Knowledge and Lifelong Learning Skills Project.

United Nations Development Program. (2016b). Initial findings from the review of technical and vocational education and training policy 2012. Kathmandu: Support to Knowledge and Lifelong Learning Skills Project.

Yin, R. K. (2018). Case study research and applications (6th ed.). Los Angeles, CA: Sage. 